\title{
Identifying damage on a bridge using rotation-based Bridge Weigh-In-Motion
}

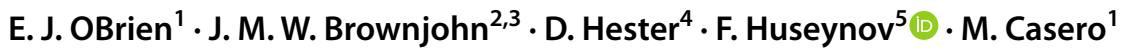

Received: 6 April 2020 / Revised: 2 September 2020 / Accepted: 9 October 2020 / Published online: 23 October 2020

(c) The Author(s) 2020

\begin{abstract}
Bridge Weigh-in-Motion (B-WIM) systems use the bridge response under a traversing vehicle to estimate its axle weights. The information obtained from B-WIM systems has been used for a wide range of applications such as pre-selection for weight enforcement, traffic management/planning and for bridge and pavement design. However, it is less often used for bridge condition assessment purposes which is the main focus of this study. This paper presents a bridge damage detection concept using information provided by B-WIM systems. However, conventional B-WIM systems use strain measurements which are not sensitive to local damage. In this paper the authors present a B-WIM formulation that uses rotation measurements obtained at the bridge supports. There is a linear relationship between support rotation and axle weight and, unlike strain, rotation is sensitive to damage anywhere in the bridge. Initially, the sensitivity of rotation to damage is investigated using a hypothetical simply supported bridge model. Having seen that rotation is damage-sensitive, the influence of bridge damage on weight predictions is analysed. It is shown that if damage occurs, a rotation-based B-WIM system will continuously overestimate the weight of traversing vehicles. Finally, the statistical repeatability of ambient traffic is studied using real traffic data obtained from a Weigh-in-Motion site in the U.S. under the Federal Highway Administration's Long-Term Pavement Performance programme and a damage indicator is proposed as the change in the mean weights of ambient traffic data. To test the robustness of the proposed damage detection methodology numerical analysis are carried out on a simply supported bridge model and results are presented within the scope of this study.
\end{abstract}

Keywords Bridge $\cdot$ Damage detection $\cdot$ Rotation $\cdot$ Bridge weigh-in-motion $\cdot$ B-WIM $\cdot$ WIM $\cdot$ Ambient traffic

\section{Introduction}

F. Huseynov

fh392@cam.ac.uk

1 School of Civil Engineering, University College Dublin, Newstead, Belfield, Dublin D04 V1W8, Ireland

2 Vibration Engineering Section, College of Engineering, Mathematics and Physical Sciences, University of Exeter, North Park Road, Exeter EX4 4QF, UK

3 Full Scale Dynamics LTD, Kay Building North Park Road, Exeter EX4 4QF, UK

4 School of Natural and Built Environment, Queen's University Belfast, Stranmillis Road, Belfast BT9 5AG, Northern Ireland, UK

5 Department of Engineering, University of Cambridge, Trumpington Street, Cambridge CB2 1PZ, UK
While the bridge stock around the world is ageing, freight transport is growing and the demand on transport infrastructure is therefore increasing. Bridges are typically designed to maintain their functionality for 75-100 years of service life. A recent survey of European's highway infrastructure has revealed that almost half of Europe's bridges were built before the 1960s and have now exceeded their planned service life [1]. During this period, they were subject to degradation processes due to environmental and loading conditions. Therefore, accurate bridge condition assessment methods are needed to verify the safety of older structures.

In the simplest term, SHM systems can be categorised in four levels based on the type of information they are capable of providing [2]. These four levels are as follows:

- Level I: Identifying the presence of damage. 
- Level II: Detecting the presence of damage and its location.

- Level III: Quantifying the severity of damage and its location.

- Level IV: Quantifying the reserve capacity of the structure.

A new Level I bridge condition assessment method is proposed in this paper that uses a Bridge Weigh-in-Motion (B-WIM) algorithm. A conventional B-WIM system is designed to estimate the axle weights of vehicles traversing a bridge structure. It typically consists of sensing equipment, traditionally strain transducers [3, 4], to record bridge deformations and identify the vehicle's speed and axle spacings. While traditionally strains have been used as the main parameter in the B-WIM systems more recently authors have proposed using displacement [5] and rotation [6] measurements. In this paper, rotation is measured at the support as it is sensitive to bridge damage away from the sensor location. The concept is that a change in the population of inferred vehicle weights is an indication that the bridge is damaged.

The B-WIM algorithm first proposed by Moses [7], which forms the basis of most installed B-WIM systems, is based on the use of influence lines (IL's). The IL's of a structure are typically obtained during installation by measuring the responses to a vehicle with known axle weights and spacings. Once calibrated in this way, the system finds the axle weights of passing vehicles by best fitting measurements to the corresponding theoretical responses. The formulations used in B-WIM system are further explained in the following sections. B-WIM technology is mostly used for road bridges; however in recent studies it has also been successfully applied to a railway bridge [8]- [10].

Weigh-in-Motion systems were initially developed for overload monitoring and control purposes. However data gathered from WIM systems have also been used for other purposes such as updating notional traffic load models for bridge design [11], developing a site-specific bridge load model [12], calculating a dynamic amplification factor for bridge design and/or assessment [13], planning and management of road infrastructure [14], and assessment of fatigue load calculations [15-17]. In recent studies, it has also been investigated for SHM purposes. Cantero and Gonzalez propose a new damage detection method using combined information provided by pavement-based and bridge-based WIM systems [18]. It has been shown numerically that when damage occurs, a B-WIM system miscalculates the weight of the traversing vehicle, whereas the pavement based WIM system, which is not sensitive to bridge damage, estimates vehicle loads without bias. In this study, a damage indicator is defined as the relative difference in gross vehicle weight inferred by the two systems. In [19] the authors introduce a fictitious weightless axle, termed a Virtual Axle, in the
Weigh-in-Motion algorithm to derive a damage indicator. In essence, if damage occurs then the B-WIM algorithm overestimates the weight of the virtual axle. In another study, data obtained from a B-WIM system are used as input to an artificial neural network to evaluate the condition of a bridge [20]. After a learning phase, this system is able to detect the occurrence of damage by predicting the bridge response and comparing it with the measurements. It is of note that, in all of these studies, the use of B-WIM technology for SHM purposes is limited to integral bridges. This is because the B-WIM systems investigated in these studies use strain sensors to measure bridge deformations, which are only sensitive to local damage at the sensor location in a statically determinate structure. However, to make B-WIM SHM applicable for other bridge types (e.g., simply-supported bridges) it makes more sense to use displacement- or rotation - based B-WIM for damage detection. Fortunately, while conventional B-WIM systems use strain measurements, the concept has also been successfully applied using deflection [5] and rotation measurements [6], which are sensitive to damage remote from the sensor location [21].

This paper proposes a novel approach of using rotationbased Bridge Weigh-in-Motion for damage detection. Broadly speaking, in the proposed method, damage is manifested as an increase in the rotation signals measured at the bridge supports during the crossing of a typical vehicle. However, rather than looking directly at rotation values which are subject to natural variations, in this paper the rotation measurements are used in a B-WIM algorithm to predict the axle weights of the passing vehicles. If damage occurs, the system will show an increase in the inferred weight. Unlike directly measured rotation where the 'healthy-bridge answer' is unknown, when working with a traffic population, the healthy-bridge answer can be found-it is the statistical distribution of vehicle weight data for the site.

A B-WIM algorithm using rotation measurements is outlined in Sect. 2, along with the effect of damage on inferred axle weights. In Sect. 3, the statistical repeatability of ambient traffic data obtained from a WIM site in the U.S. is investigated. Finally, capability of the proposed method to detect local damage on a bridge structure is demonstrated through numerical analysis on a 3-D FE bridge model.

\section{Influence of damage on B-WIM results}

This section develops the theoretical basis for the proposed approach. Section 2.1 describes how B-WIM can be implemented using rotation data measured at the end of a bridge deck; Sect. 2.2 shows how damage will affect the magnitude of this rotation and Sect. 2.3 looks specifically at the effect of damage on the predicted load. 


\subsection{Bridge weigh-in-motion using rotation}

Unlike strain in a determinate structure, rotation is influenced by the stiffness in all parts of a bridge deck. Hence, in principle, no matter where the damage is, it will have some effect on the rotation measurement.

B-WIM can be implemented for any measurable quantity that is a function of traffic load. Here, a B-WIM algorithm is presented where rotation is the measured quantity. This formulation follows the same principles as B-WIM using strain and, as such, is based on Moses' algorithm [7]. Total (static) rotation at an instant in time, due to a moving vehicle, can be calculated by combining the contributions of each axle on the bridge. This results in a system of equations defining the rotation time history:

$\left[\theta^{\mathrm{T}}\right]_{\mathrm{K} \times 1}=[\mathrm{IL}]_{\mathrm{K} \times \mathrm{N}} \times[\mathrm{P}]_{\mathrm{N} \times 1}$

where $\left[\theta^{\mathrm{T}}\right]$ is a vector comprising of total theoretical rotation values, $[\mathrm{IL}]$ is a matrix containing influence line ordinates for each axle and each instant in time, $[\mathrm{P}]$ is the vector of axle weights, $K$ is the total number of sampling points (scans) and $N$ is the number of axles.

In reality, the response of a structure to a moving load consists of not only static but also dynamic components which oscillate about the static response. Typically, it takes about a second for a vehicle travelling at a highway speed limit to cross a short- to medium-span bridge. Given that the measurements during a vehicle pass are recorded at a high sampling frequency (e.g., $256 \mathrm{~Hz}$ ) and the time history data contain many data points, Moses proposed an error function, $E$, defined in Eq. (2) as the sum of squares of differences between the measured and theoretical responses, to smooth out the dynamic components.

$E=\sum_{k=1}^{K}\left[\theta_{k}^{M}-\theta_{k}^{T}\right]^{2}$

where $k$ is the scan number and $\theta_{\mathrm{k}}{ }^{\mathrm{M}}$ is the measured rotation (including both static and dynamic components) at scan $k$.

Equation 1 is substituted into Eq. 2 and the error function is minimised with respect to individual axle weights, $\mathrm{P}_{\mathrm{i}}$, by setting partial derivatives to zero. This leads to Eq. (3), which forms the basis of most current B-WIM systems:

$[\mathrm{P}]_{\mathrm{N} \times 1}=\left([\mathrm{IL}]_{K \times \mathrm{N}}^{T} \times[\mathrm{IL}]_{\mathrm{K} \times \mathrm{N}}\right)^{-1} \times[\mathrm{IL}]_{K \times \mathrm{N}}^{T} \times\left[\theta^{\mathrm{M}}\right]_{\mathrm{K} \times 1}$

In summary, B-WIM is an inverse type problem where deformations are measured and the axle loads causing the deformations are calculated by minimising the sum of squared differences between theory and measurement. The influence line clearly plays a central role. It describes the response of the bridge at a particular location to a unit point load passing overhead. It is a physical property dependent on the material and geometric properties as well as the boundary conditions of the structure. Since the boundary conditions of many bridges lie between ideal simply supported and fully fixed, the true IL of the structure should be determined during the calibration process before any B-WIM system becomes operational. In practice, the IL of a structure is obtained from a vehicle with known axle weights and spacings passing over the bridge at a known traffic speed [22]. Once the influence line for a structure is known, then the [IL] matrix can be formed for any vehicle based on its axle configuration and speed, and axle weights can be calculated by applying Eq. (3).

The approach of B-WIM using rotation can be applied to any type of bridge structure. As a general rule, inclinometers or other rotation measuring devices, should be placed at locations where the magnitude of measurements is greatest as this maximises the signal to noise ratio. For strain or deflection based B-WIM systems, measurements are usually at mid-span. For the rotation-based B-WIM, on the other hand, the sensors for simply supported bridge structures are best located at one or both supports. In this section, the feasibility of using the B-WIM system for damage detection method is demonstrated using numerical simulations of a simply supported bridge. The Finite Element (FE) model used for the simulations is shown in Fig. 1a. Hypothetical inclinometers are placed at support locations on both sides.

\subsection{Sensitivity of rotation to damage}

Based on the Moment-Area theorem, the change in rotation between any two points along the length of the structure is equal to the corresponding area under the curvature or $M / E I$ diagram, where $M$ is moment. It follows that if there is a change in structural stiffness, EI, either globally or locally, at any location along the length of the structure, a change in rotation will result. This is illustrated in Fig. 1, which shows the rotational responses at the ends of a $20 \mathrm{~m}$ long simply supported bridge to the passage of a 2-axle truck.

The flexural properties of the bridge are those of a structure $10 \mathrm{~m}$ wide with 9 No $\mathrm{Y} 3$ precast concrete beams spaced at $1.25 \mathrm{~m}$ centres joined by a $160 \mathrm{~mm}$ thick deck slab [23]. This gives a total depth of $1060 \mathrm{~mm}$ and a second moment of area of $0.76 \mathrm{~m}^{4}$ and a total cross sectional area of $5.2 \mathrm{~m}^{2}$. Young's modulus is taken as $35 \mathrm{GPa}$. The moving vehicle has front and rear axle weights of $60 \mathrm{kN}$ and $80 \mathrm{kN}$, respectively, spaced $4 \mathrm{~m}$ apart. Damage is modelled as a local reduction in stiffness over $1 \mathrm{~m}$ (5\% of the bridge length) at mid-span with various levels of severity: $10 \%, 30 \%$ and $50 \%$.

Figure 1(a) is the bridge elevation while Fig. $1 \mathrm{~b}$ and c show the rotation "recorded" at inclinometers placed at the left and right hand supports, respectively as the vehicle 
Fig. 1 Effect of damage on the rotation experienced in a simply supported bridge, a sketch of a hypothetical bridge under 2 axle moving load. b Rotation recorded at point $\mathrm{A} \mathbf{c}$ rotation recorded at point $\mathrm{B}$ a

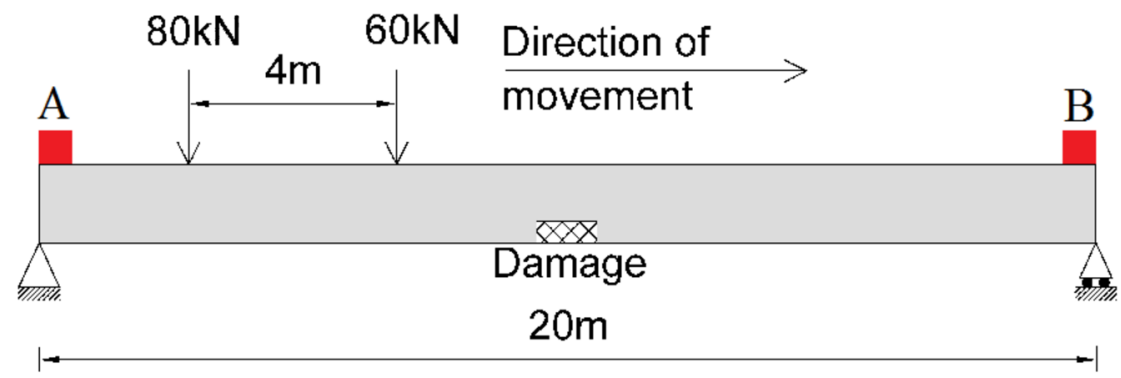

b

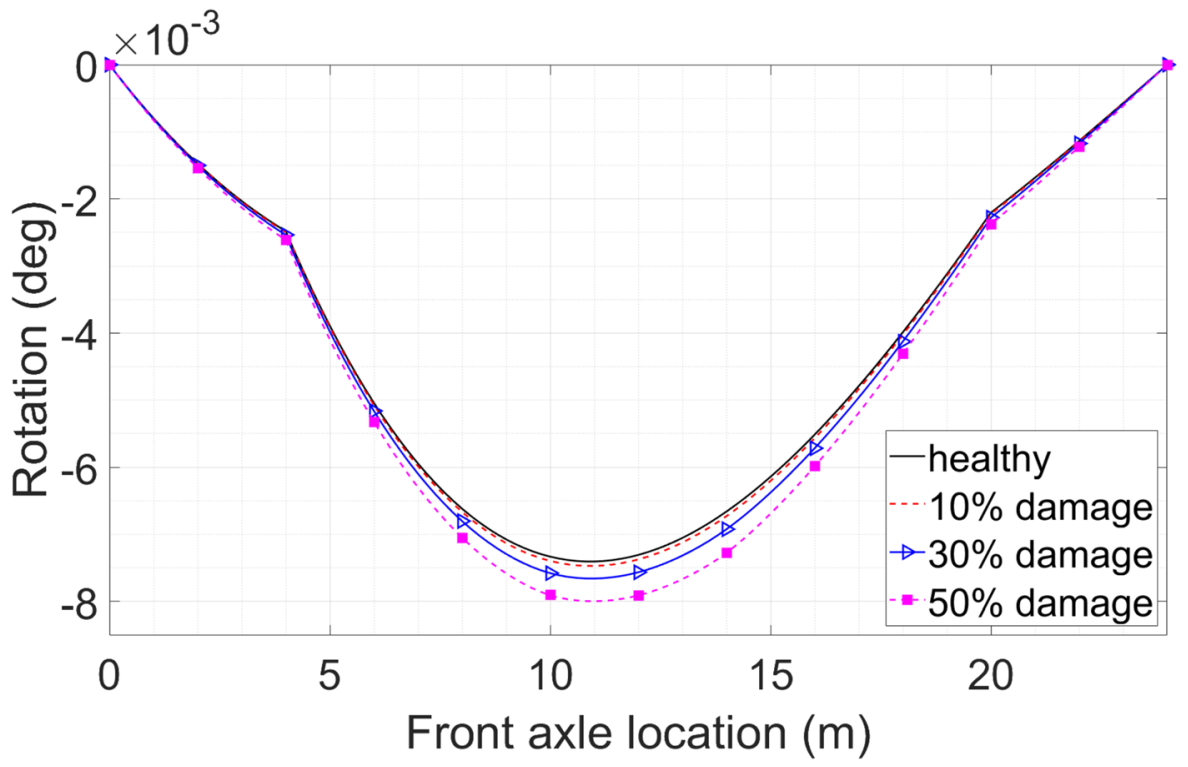

c

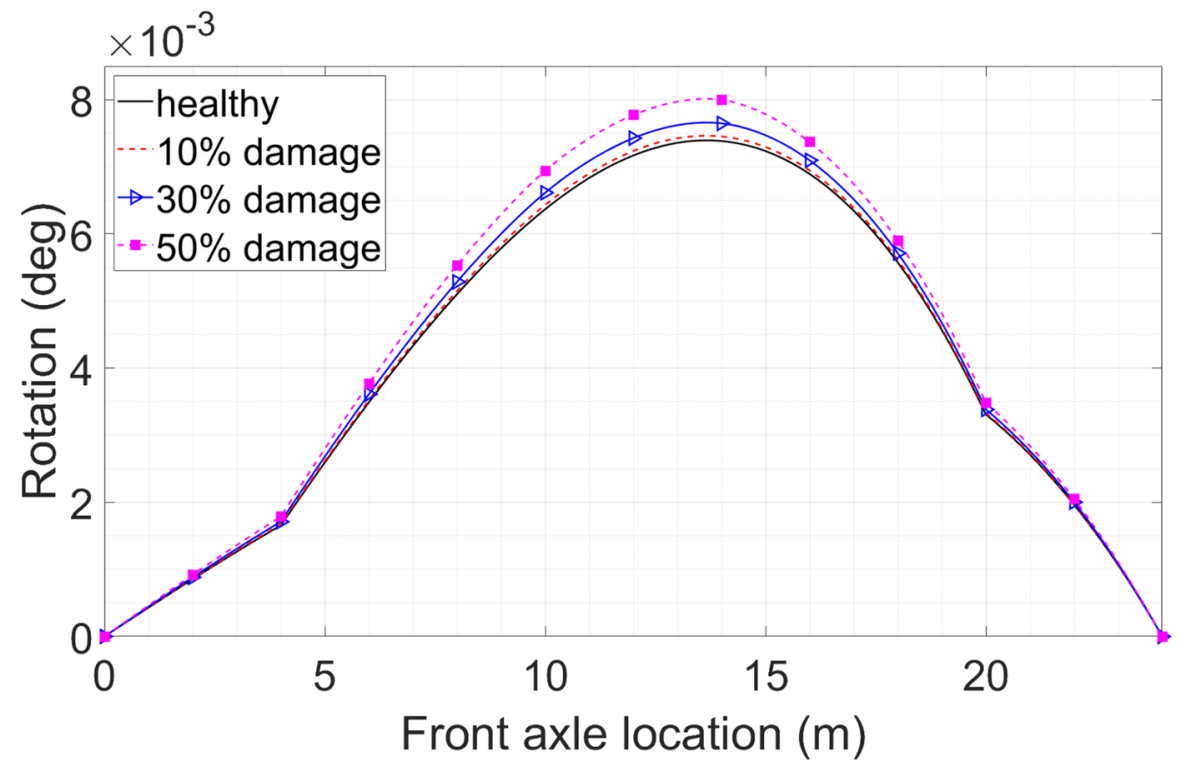

passes the healthy and damaged bridges. Discontinuities can be seen as axles arrive on and leave the bridge and the rotations are clearly greater for the damaged cases. The magnitude of rotations obtained from the numerical model is around $8 \times 10^{-3}$ degrees which is feasible to measure using the state-of-art sensors. In the last decade, the performance and accuracy of inclinometers have been significantly improved, and it is now possible to measure inclinations to a microradian ( $10^{-6}$ radians) accuracy [24-27]. An in-depth investigation of the sensitivity of rotation measurements to damage is presented in [28].

To show that rotation measurement is feasible on real bridges, Fig. 2 shows field measurements for a 4-axle truck crossing a bridge that spans $17.28 \mathrm{~m}$ over a canal. The 
a

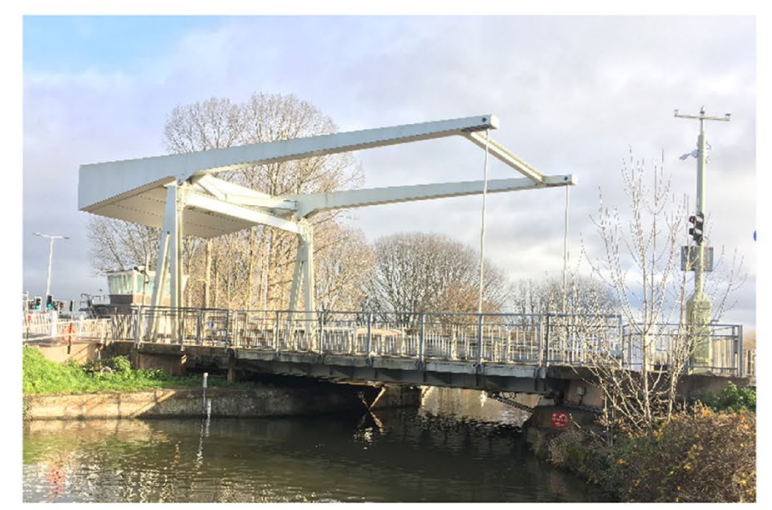

c

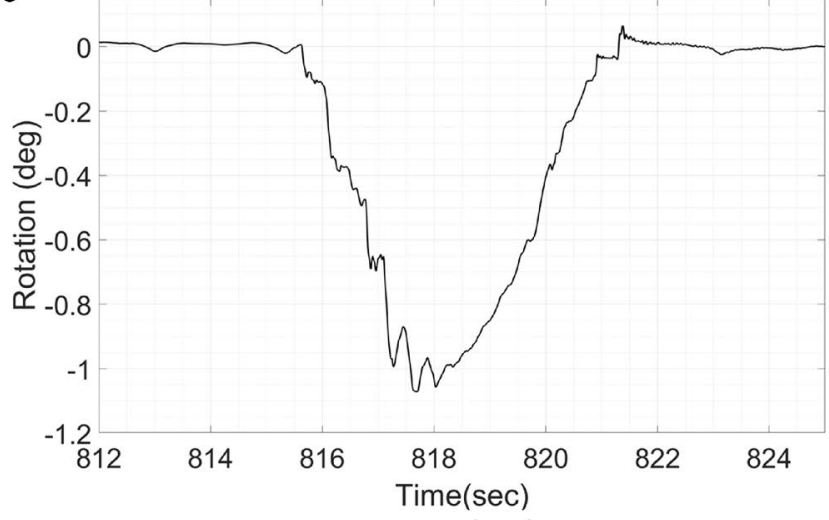

Fig. 2 Example of rotation measurements recorded in the field, a elevation of the bridge, $\mathbf{b}$ four axle 32 tonne truck used during load testing, $\mathbf{c}$ rotation time history recorded using an inclinometer placed

bridge is a lifting bascule bridge, but once in the down position, the bridge effectively behaves as simply supported. These responses were measured using two uniaxial Honeywell QA-750 accelerometers, which were placed at each support locations. Recent works examined the attributes of these sensors in the context of SHM applications $[29,30]$. One of the capabilities of these high-end DC accelerometers is that they allow measurement of the DC component of the signal with very low noise at $0 \mathrm{~Hz}$ in the frequency domain, i.e., they can sense gravity under quasi-static conditions. Since the output of an accelerometer obeys a sinusoidal relationship when it is rotated through gravity, such as when it is pointed in the horizontal direction it records $0 \mathrm{~g}$ whereas when it is placed in the vertical direction it reads $\pm 1 \mathrm{~g}$ based on the direction of axis of measurements, the conversion from acceleration to rotation could be obtained using the inverse sine function as given in Eq. (4).

$\theta=\sin ^{-1}(\operatorname{Acc}[g]) \times \frac{\pi}{180}$ b

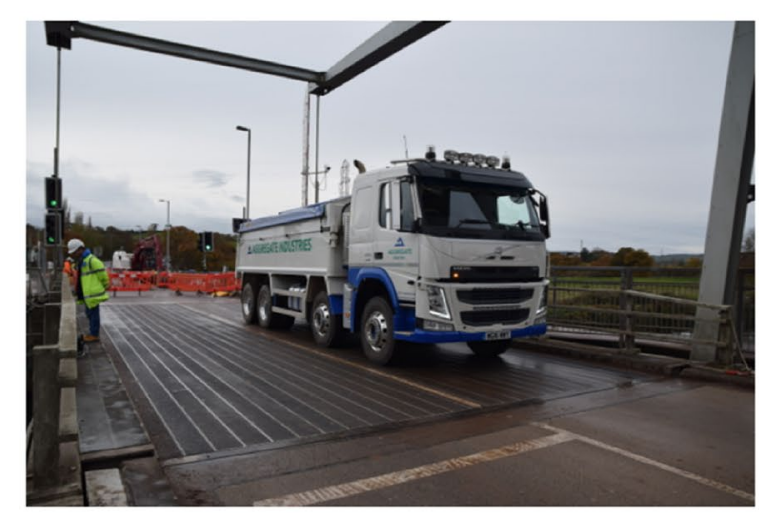

d

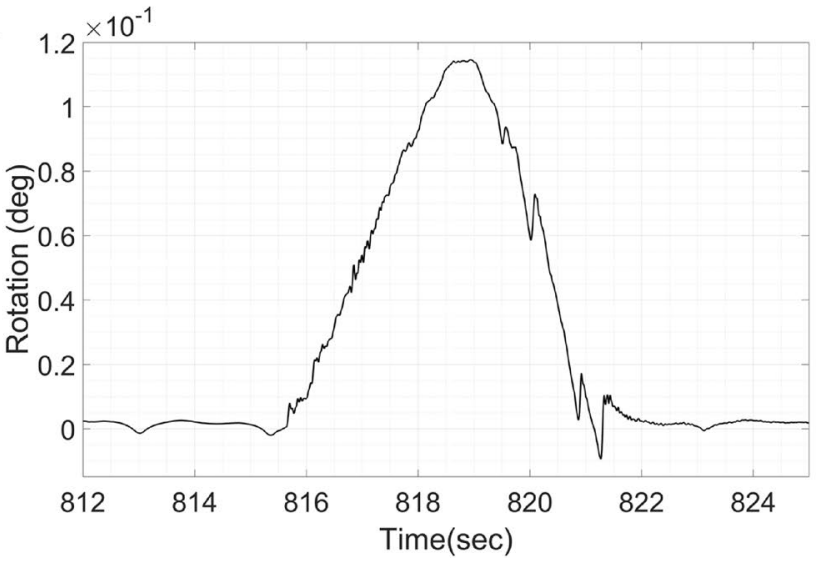

near the left support $\mathbf{d}$ rotation time history recorded using an inclinometer placed near the right support

where the estimated rotation value, $\theta$, is in degrees.

In practice, as well as experiencing rotation due to the static effects of the load, the bridge will also contain some level of dynamic response and measurement noise. This can be filtered by applying a low pass filter on the raw acceleration data.

The accuracy of rotation measurements obtained using accelerometers has been investigated by the authors in recent studies [31-33]. In [31, 32], the authors instrumented a railway bridge with QA-750 accelerometers to measure rotations at five locations along the bridge span. Using this [34], they calculated the midspan deflections of the bridge deck. Calculated midspan deflections were later validated with deflections measured with an optical camera system. The comparison of deflection values obtained using rotation measurements with direct measurements (i.e., optical camera) provided some evidence of the degree of accuracy of the rotation measurements (using QA-750 accelerometers). In another study, the authors conducted extensive laboratory experiments on a bridge model to validate the robustness of a novel bridge damage detection methodology using direct rotation measurements [33]. The results showed that the 
rotation measurement technique described above can sense the effect of damage on the bridge model for a damage level as low as $7 \%$ change in stiffness applied over a length of $2.5 \%$ of the bridge span.

\subsection{Effect of damage on predicted load}

As demonstrated in the previous section, damage in a bridge structure results in higher magnitudes of rotation for a given loading. Assuming that the structure is not recalibrated after damage, then the B-WIM algorithm for the damaged case infers loads using the 'healthy' influence line but larger measured rotations (Eq. (3)):

$\left[\mathrm{P}^{*}\right]_{\mathrm{N} \times 1}=\left([\mathrm{IL}]_{K \times \mathrm{N}}^{T} \times[\mathrm{IL}]_{\mathrm{K} \times \mathrm{N}}\right)^{-1} \times[\mathrm{IL}]_{K \times \mathrm{N}}^{T} \times\left[\theta^{\mathrm{M}^{*}}\right]_{\mathrm{K} \times 1}$

where $\left[\theta^{\mathrm{M} *}\right]_{\mathrm{K} \times 1}$ is a vector containing the measured rotations for the damaged case $\left(\theta^{\mathrm{M} *}>\theta^{\mathrm{M}}\right)$ and $\left[\mathrm{P}^{*}\right]_{\mathrm{N} \times 1}$ is a vector consisting of the corresponding inferred axle weights. Since the [IL] matrix in the formulation remains the same as the initial (healthy) case but the magnitudes of rotations $\left(\theta^{\mathrm{M} *}\right)$ increase due to the damage, the B-WIM algorithm will consistently overestimate the Gross Vehicle Weight (GVW).

To further investigate the effect of damage on the B-WIM analysis, numerical analysis was carried out using the bridge and vehicle models presented in Fig. 1 of Sect. 2.2. The damage was simulated at three different locations, at $1 / 4 L$, $1 / 2 L$ and $3 / 4 L$, as $30 \%$ loss in stiffness over a $1 \mathrm{~m}$ length. The rotation time history under the two axle truck was obtained from the numerical model for the healthy and damaged cases using the hypothetical inclinometer placed at the left hand support. The axle weights were then back-calculated using the healthy influence line for the healthy and damaged cases, respectively. Figure 3 shows the axle weights calculated by the algorithm for the healthy case and bridges with damage at three separate locations. Note the $\mathrm{x}$ and $\mathrm{y}$ axes in the figure show the calculated weights for axles 1 and 2, respectively. For the healthy case, the correct axle weights are found, i.e., $60 \mathrm{kN}$ and $80 \mathrm{kN}$ for axles 1 and 2 respectively, (see Fig. 1). For the damaged cases, axle weights are generally but not always overestimated. The error in Axle 1 weight is greater than the error in Axle 2 when damage is at $1 / 4$ span. For damage at $3 / 4$ span, the error in Axle 2 weight is greater and the Axle 1 weight error is actually slightly negative. However, the GVW estimated for all damaged bridge states are greater than the actual GVW of the simulated vehicle.

Figure 3 shows vectors representing the changes in inferred axle weights due to damage in Axle 1/Axle 2 space. If there were a pavement based WIM system beside the bridge, (see, for example, [18]), then it would be relatively easy to identify damage from this plot. The relative difference in the magnitudes of the weights inferred by the two systems indicates the

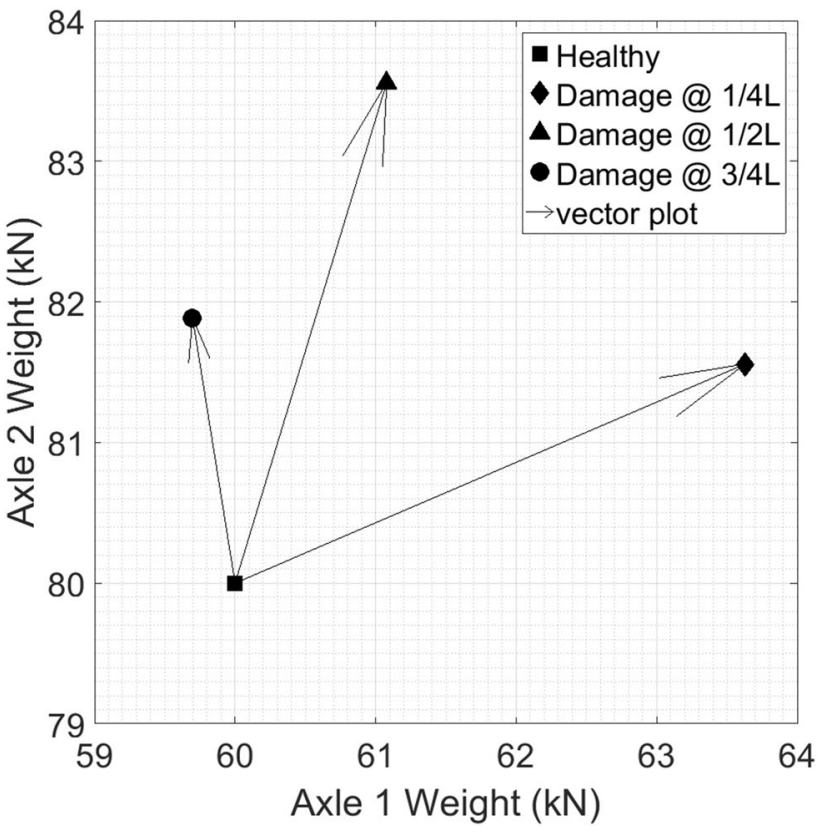

Fig. 3 Vector plot of change in axle weights in W1/W2 space due to damage

severity of damage and the inclination of the vector gives an indication of its location. However, WIM systems are expensive to install and are often not accurate for individual vehicle weights. Therefore, a method for inferring damage that does not require an adjacent pavement-based WIM system is proposed and investigated in Sects. 3 and 4.

It should be noted that the bridge influence line might also be affected by events other than local (bridge strike) damage such as bearing failure or a possible change in road surface profile due to a deteriorating pavement condition. The failure of a bearing intended to allow free rotation would have a significant effect on the whole shape of a rotation IL. While it should be possible in many cases to distinguish between bridge strike and bearing damage, the objective in this paper is simply to detect a change which prompts further investigation.

Pavement condition is known to affect the accuracy of B-WIM so a deterioration of the pavement may affect the damage indicator. However, B-WIM systems have been in place at some sites for years without significant loss of accuracy. It is therefore not anticipated that pavement deterioration will be a particular problem in most cases.

\section{Ambient traffic}

While the weights of individual vehicles crossing a bridge are generally not known, there are statistical features of the population of vehicle weights at a site that are repeatable. 
Therefore, in this section, a population of 5-axle trucks is considered, together with the influence that bridge damage has on the population of inferred weights. Data from the U.S. Federal Highway Administration's Long-Term Pavement Performance (LTPP) programme is used for the population of trucks. Through the LTPP, data have been collected at various sites in North America since 1989. In 2001, quality control procedures were centralised and improved through a national pooled-fund study [35]. Since then "research quality" data are being collected at 19 LTPP sites in 17 different states across the U.S. The WIM technologies currently being used for traffic data collection include only bending plate, load cell, and piezo-quartz, all of which meet the research quality data standard. Results from the validation tests are presented in Table 1, which shows the accuracy level of the WIM systems instrumented under the LTPP programme.

For the purpose of this study, 4 years of data (2009-2012) collected from Lane 2 of the Virginia site, are investigated. The average total number of vehicles at the selected site is around 393,000 per year with an average daily truck traffic in the monitored lane of 1087 . The data available to the authors had already been cleaned according to federal and state regulations and only non-permit, i.e., regular truck data, were present [36]. According to LTPP standards the vehicles are categorised into 15 classes based on their axle configurations and weight distributions. In general, excluding the lightest vehicles ( $\mathrm{GVW}<3.5$ tonnes), the typical distribution of vehicle by class at the selected site is shown in Fig. 4. Vehicle Class 9 is a 5-axle semi-trailer consisting of a 3-axle tractor (steer axle + tandem) and a trailer with a 2nd tandem [37]. This vehicle class was selected for further study since it is the predominant type of truck configuration at the site.

The degree of variability in the Class 9 gross weight distributions from year to year is illustrated in Fig. 5. It can be seen that the peaks at around 16 tonnes and 35 tonnes, which correspond to unloaded and loaded trucks, respectively, are consistent from year to year. Figure 6 shows the variability in monthly average tandem weights of loaded trucks, defined here as trucks with GVW $>30$ tonnes, and the relationship between the weights of the two tandems. Tandem 1 on the tractor and tandem 2 on the trailer are plotted on the abscissa and ordinate axes, respectively. As would be expected, there

Table 1 Accuracy of LTPP data obtained from the validations tests (95\% confidence level) [35]

\begin{tabular}{lll}
\hline Parameter & Accuracy & \\
\cline { 2 - 3 } & Data from 2001 & Data from 2005 \\
\hline Gross weight & $-18 \%$ to $+30 \%$ & $0.2 \% \pm 8.2 \%$ \\
Tandem axles & $-26 \%$ to $+41 \%$ & $0.0 \% \pm 10.2 \%$ \\
Single axles & $-31 \%$ to $+38 \%$ & $1.2 \% \pm 10.0 \%$ \\
\hline
\end{tabular}

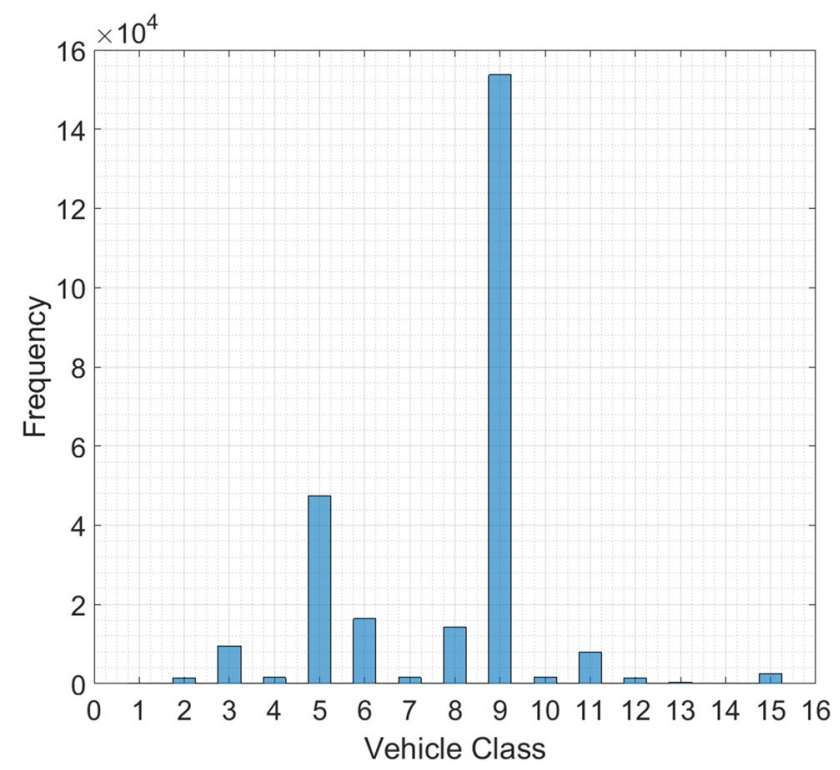

Fig. 4 Histogram of vehicle Classes of traffic data collected during 2009 on Lane 2 at LTPP site in Virginia [37]

is more variability in tandem weights than GVW. As Tandem 1 is part of the tractor and is influenced by engine weight as well as payload, it is less variable than Tandem 2 . The dashed curve encloses the $95 \%$ confidence interval for the 48 points. The red and blue arrows in the figure represent the major and minor axes of the confidence area. These vectors indicate the directions in which the average tandem weights vary and are defined by the covariance matrix. Specifically, the arrows are the eigenvectors of the covariance matrix of the data and their lengths represent the eigenvalues. The hypothesis is that any average tandem weight combination that falls outside the $95 \%$ confidence interval is anomalous and indicates that the bridge may be damaged which would induce errors in the calculated weights. To test this,

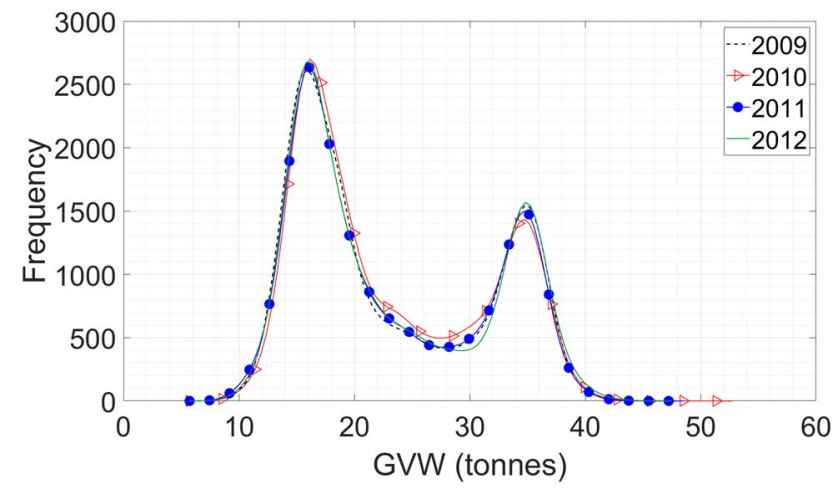

Fig. 5 Repeatability of Class 9 vehicle data. Annual histograms of Gross Vehicle Weight (GVW) 


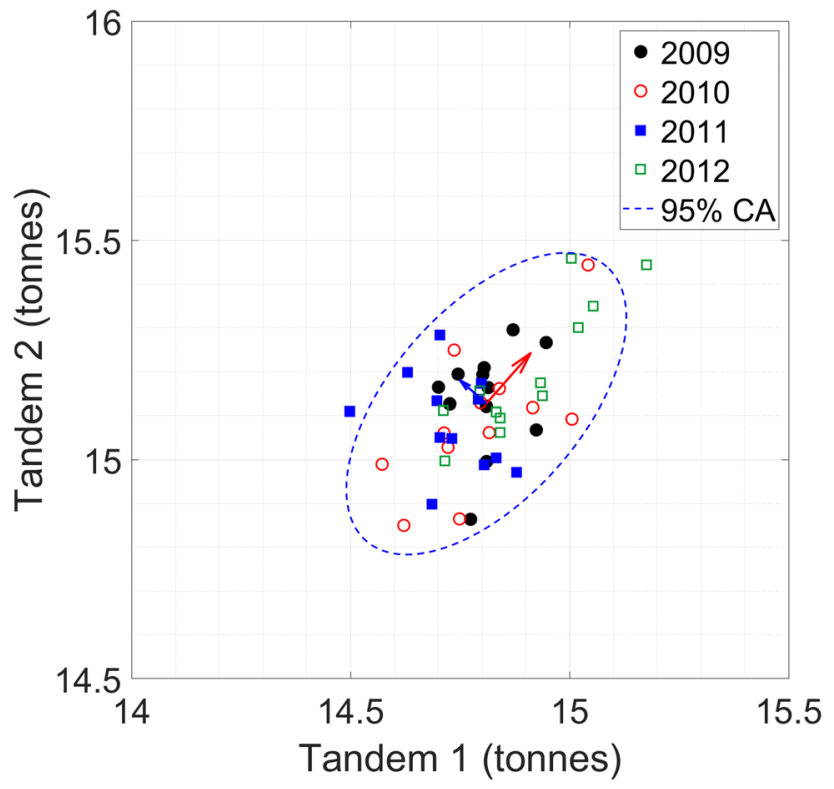

Fig. 6 Monthly average tandem weights of loaded Class 9 vehicles at Virginia site (Tandem 1 in tractor; Tandem 2 in trailer). There are 12 markers in each colour, corresponding to the 12 months of that year numerical simulations are carried out which are explained in detail in the following section.

\section{Method verification on a 3-D FE model}

A 3-D FE bridge model is developed using Nastran Software to test the capability of the proposed bridge damage detection methodology under more realistic conditions. The hypothetical structure is modelled as a $20 \mathrm{~m}$ long and $11 \mathrm{~m}$ wide simply supported bridge, composed of a $0.2 \mathrm{~m}$ thick solid slab and $0.9 \mathrm{~m}$ deep 10 beams spaced at $1 \mathrm{~m}$ apart. Figure 7 shows the elevation and the cross-sectional view of the bridge model.

The slab is represented by $1 \mathrm{~m} \times 1 \mathrm{~m} 2$-D plate elements while the beams are modelled as a series of 1-D beam elements. The modulus of elasticity for plate and beam elements are assigned as $30 \mathrm{GPa}$ and $33 \mathrm{GPa}$, respectively, to simulate in situ concrete slab and precast beams. The Poisson ratio is assigned as 0.15 and the shear modulus is calculated assuming an isotropic material for all element types. The material density is set at $2500 \mathrm{~kg} / \mathrm{m}^{3}$ both for the slab and the beams. To simulate the presence of a diaphragm at both ends of the bridge, the second moment of area of the beams is set higher for elements close to the supports in comparison to the rest of elements. As a result, the $2 \mathrm{nd}$ moment of area of the beam elements between $x=1 \mathrm{~m}$ and $x=19 \mathrm{~m}\left(I_{b}\right)$ equalled $0.0685 \mathrm{~m}^{4}$ while in the ranges $x=[0,1]$ and $[19,20] \mathrm{m}\left(I_{\mathrm{b} \text {,supports }}\right)$ it was increased by up to $0.108 \mathrm{~m}^{4}$.
Fig. 7 3-D FE bridge model. a plan view b cross-sectional view $(\mathrm{A}-\mathrm{A})$

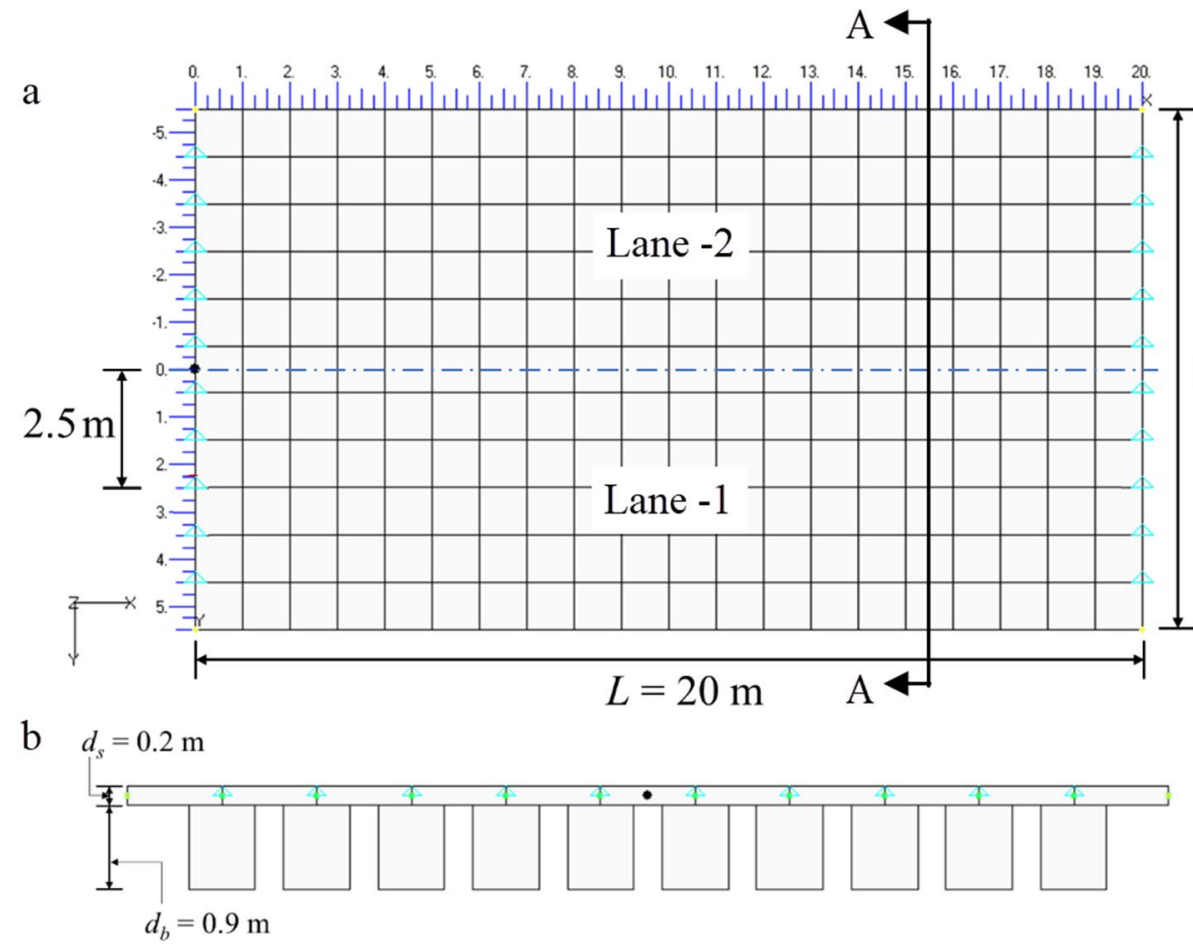


Three damage scenarios are investigated in this study where damage is modelled at $\mathrm{L} / 4, \mathrm{~L} / 2$ and $3 \mathrm{~L} / 4$ span locations, one at a time. In each test scenario, damage is modelled as a reduction in the flexural stiffness of beam elements (i.e., slab elements remain intact) over $3 \mathrm{~m}$ extent. At each damage location, girders consist of three elements, each $1 \mathrm{~m}$ long. The stiffness of the central beam element is reduced by $40 \%$ whereas the stiffnesses of the two adjacent elements are reduced by $13 \%$. Since the slab elements remain intact, the corresponding equivalent damage levels on the composite precast beam and "in-situ" slab section are approximately $32 \%$ and $10 \%$ for central and two adjacent damaged elements, respectively. In the transverse direction, damage is modelled along the full width of Lane-1 (i.e., half of the bridge width).

Real traffic data obtained at the Virginia WIM site in 2009-2012 (described above) are used to simulate ambient traffic. The bridge model is loaded with the traffic population crossing along Lane-1. The hypothetical inclinometer is located at the left hand support, at the coordinate $[0 \mathrm{~m}$, $2.5 \mathrm{~m}$ ] (see Fig. 7) to record the rotation response of the bridge to a traversing vehicle. This is repeated for the healthy and the damaged cases and the rotation time history data obtained from the FE model are used to back-calculate the tandem axle weights of the traversing vehicles by applying Eqs. (3) and (5). The results are further elaborated in the following section.

\section{Results and discussions}

Figure 8 shows the average monthly inferred tandem weights for the population of Class 9 trucks for the healthy and the three damaged cases (described above) calculated using the rotation signal obtained at the coordinates, $[0 \mathrm{~m}, 2.5 \mathrm{~m}]$ (i.e., left-hand support). The circular data markers correspond to the healthy bridge while the triangular markers correspond to the damaged cases. Those months where the healthy bridge results fall outside the $95 \%$ curve are shown solid. These indicate false positives-damage is implied, but the bridge is healthy. This is because the curve is derived based on the $95 \%$ confidence area, hence some of the data remains outside of the curve. The triangular markers in the figure correspond to the damaged bridge scenarios. Open triangles are for months where the bridge is damaged and the average inferred weights confirm this to be the case, i.e., damage successfully detected. Closed triangles are for months where the bridge is damaged, but the inferred tandem weight combination falls inside the $95 \%$ curve, i.e., damaged but damage not detected.

The method can be seen to work well for damage at $1 / 4$ span (Fig. 8a), closest to the inclinometer location (i.e., lefthand support, at $[0 \mathrm{~m}, 2.5 \mathrm{~m}]$ coordinates). There are only
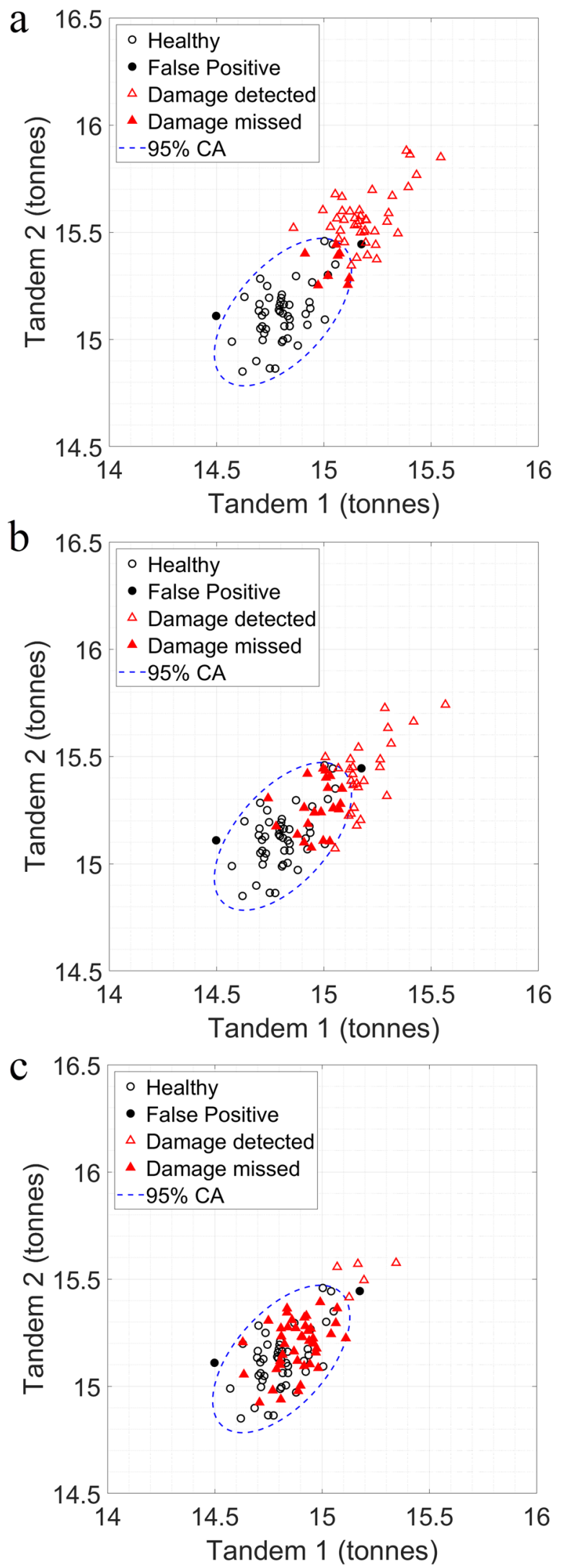

Fig. 8 Monthly average tandem weights inferred from left inclinometer signals for healthy and damaged cases. a Damage at $1 / 4$ span (b) damage at $1 / 2$ span $\mathbf{c}$ damage at $3 / 4$ span 
two false positives and seven damage-missed cases out of 48. For damage at mid-span, the number of damage-missed cases has increased to twenty (Fig. 8b) and for damage at $3 / 4$ span (Fig. 8c), there is a strong overlap between the healthy and damaged populations, making it infeasible to use this as a means of detecting damage. Another conclusion from Fig. 8 is that the ability of the proposed methodology to identify damage reduces as damage occurs further away from the sensor location. It should be noted that this is a pseudo-static analysis only. For bridges where there is significant dynamics, detecting damage may be more difficult.

Numerical analyses were carried out to further investigate the influence of damage location on inferred weight. An analysis similar to that mentioned above is carried out but this time the inclinometers are placed on both support locations (coordinates [0 m, $2.5 \mathrm{~m}]$ and [20 m, $2.5 \mathrm{~m}]$ ).
The histogram of change in GVW due to damage (inferred GVW minus true weight of a 5-axle truck) is extracted in Fig. 9 using each individual inclinometer. Figure $9 a-c$ show the weight error histograms for damage at $1 / 4 L, 1 / 2$ $L$ and $3 / 4 L$ locations using an inclinometer placed at the left hand support. Figure $9 d-f$ show the corresponding histograms for an inclinometer placed at the right-hand support. The abscissa in each figure shows the observed change in the axle weight. It can be seen in the plots that the error in GVW weight, which obviously reflects the sensitivity of a sensor location to damage, reduces when the damage is further away from the sensor location. For example, in Fig. 9a the highest frequency of error in GVW, corresponding to loaded 5 axle trucks, (second peak on the graph) is around 1.2-1.5 $t$, where the damage is simulated at $1 / 4$ span. When the corresponding vehicle weights are a

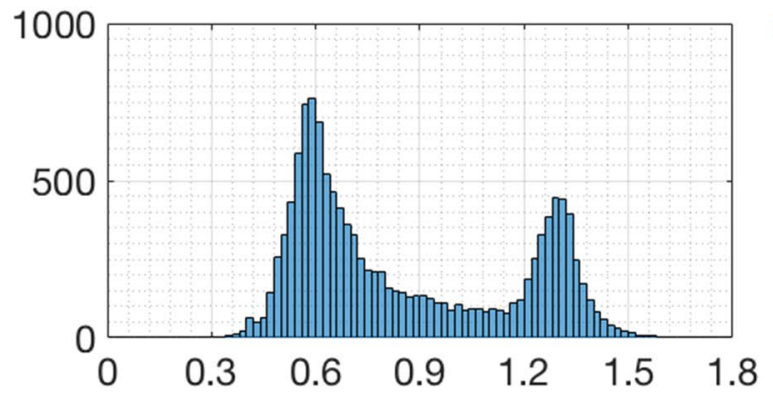

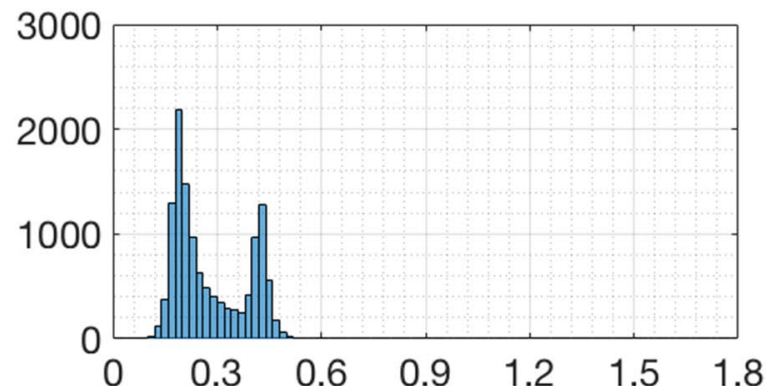

e

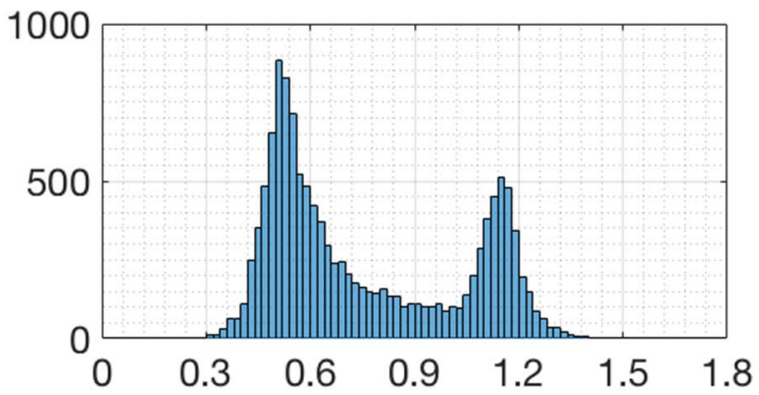

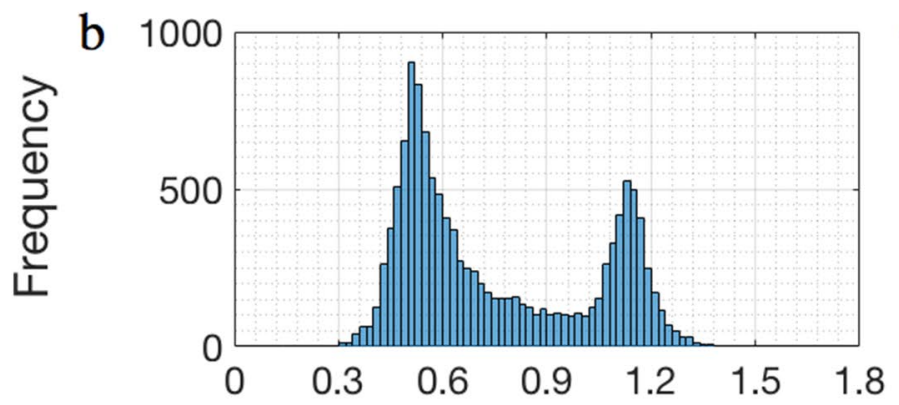

$\mathrm{f}$

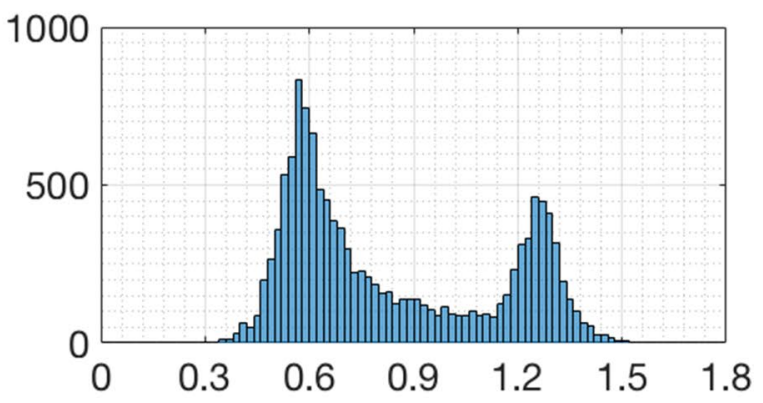

Change in GVW (tonnes)

Fig. 9 Histogram of change in GVW. Calculated using inclinometer placed at left-hand support while damage is modelled at $\mathbf{a} 1 / 4 \mathrm{~L}$ span $\mathbf{b}$ $1 / 2 \mathrm{~L}$ span $\mathbf{c} 3 / 4 \mathrm{~L}$ span locations. Calculated using inclinometer placed at right-hand support while damage is modelled at $\mathbf{d}^{1 / 4} \mathrm{~L}$ span $\mathbf{e}^{1 / 2} \mathrm{~L}$ span $\mathbf{f} 3 / 4 \mathrm{~L}$ span locations 
inferred using the rotations obtained from the inclinometer at the right-hand support (Fig. 9d) the error observed for this loaded truck peak is around $0.4 \mathrm{t}$. The implication is that the method works best when two inclinometers are used to infer weights and hence to detect damage at any location along the length of the bridge.

Having seen that the effect of damage on weight predictions is higher when the damage is closer to the sensor location, similar analyses presented in Fig. 8c are carried out for bridge damage at $3 / 4$ span where, this time, the average monthly tandem weights are calculated using the inclinometer placed at the right hand support (i.e., [20 m, $2.5 \mathrm{~m}]$ ) and corresponding results are presented in Fig. 10. While most of the $3 / 4$ span data for the damaged and healthy cases overlapped when the average monthly tandem weights were inferred using the inclinometer at the left-hand support (Fig. 8c), it can be seen in Fig. 10 that the results are considerably improved when data from the right hand support are used. There are only two false positive results and one damage-missed case out of 48 . It is therefore inferred that utilising inclinometers at two support locations makes it possible to identify damage occurring at any location along the length of the bridge structure using the proposed damage detection methodology.

It is acknowledged that measurements recorded in the field will contain a certain level of random error (noise) which needs to be considered while assessing the robustness of the proposed method. This is tested here by adding a noise vector, proposed by Zhu and Law [38]:

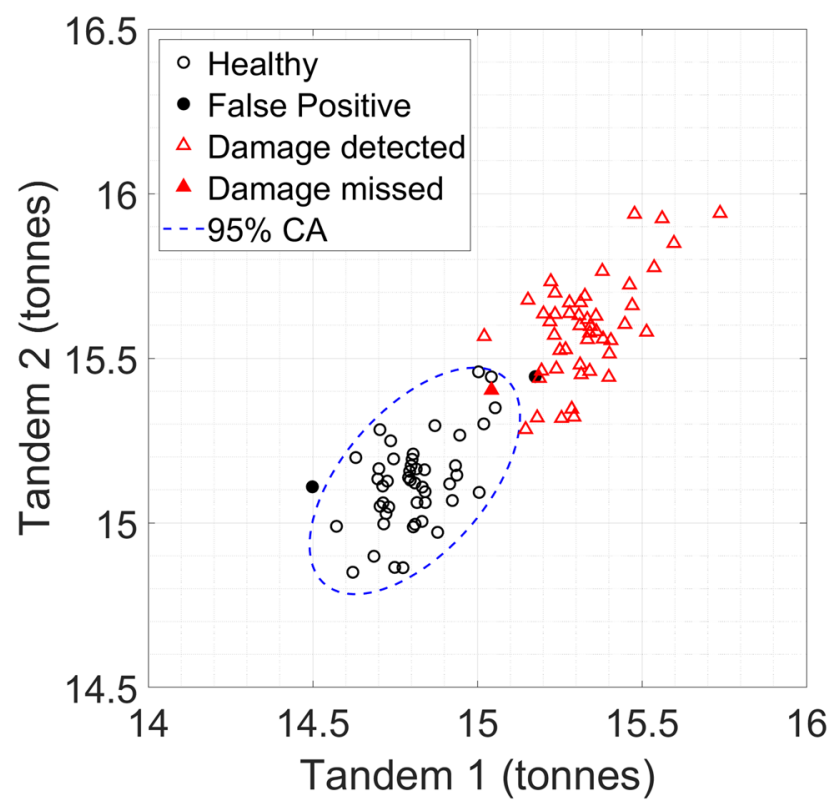

Fig. 10 Monthly average tandem weights estimated using the inclinometer placed at right hand support when the damage is at $3 / 4 \mathrm{~L}$ $\{a\}=\left\{a_{\text {calc }}\right\}+E_{p}\{N\} \sigma$

where $\{a\}$ is a vector of corrupted rotations, $\left\{a_{\text {calc }}\right\}$ is a vector of noise-free rotations, $E_{p}$ is the noise level $\{N\}$ is a standard normal distribution vector with zero mean and unit standard deviation and $\sigma$ is the standard deviation of the noise-free rotations. Figure 11 shows a typical corrupted rotation time history corresponding to a 5 axle truck with $20 \%$ noise (i.e., $E_{p}=0.2$ ) at the scan frequency, i.e., all measurements randomly perturbed.

It is noted that the algorithm proposed in this study requires very little computing power-it takes only seconds

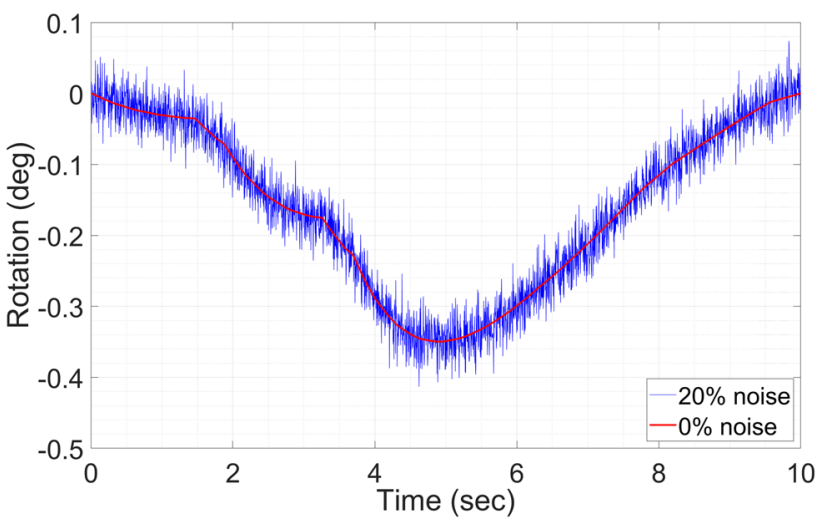

Fig. 11 Noise free and corrupted rotation time history recorded using the left inclinometer for $20 \%$ noise level under 5 axle truck loading The simulations are repeated with this added noise for each of two inclinometers placed, one at each support. While in the previous analyses, damage was simulated for all months (2009-2012) for which data were available, this time it is assumed that damage occurs at the start of the particular month of July 2012. For this case, the confidence area is derived using data collected between January 2009 and December 2011 (open black circles in Fig. 12), well before the damage occurred. The figure also shows the average monthly tandem weights inferred using the rotation signals from January 2012 onward-some corrupted by damage which occurs in July 2012. When the damage is at the $1 / 4$ span location, the average tandem weights are inferred using the inclinometer at the left hand support (Fig. 12a). When the damage is at mid-span or $3 / 4 L$ locations (Fig. 12b and c), the weights are calculated using the inclinometer at the right hand support. In practice where damage location is unknown, it is anticipated that data from both sensors would be analysed and any anomalous results would result in further investigation. For all 6 months and all three possible damage locations, average monthly tandem weights between January and June 2012 (blue solid dots in Fig. 12), fall inside the $95 \%$ confidence area, confirming that the bridge is healthy. Starting from July 2012 when the damage occurs at quarter and threequarter span locations (i.e., Fig. 12a and c), the inferred average monthly tandem weights fall outside the confidence area, implying the existence of damage. For the damage scenario modelled at the midspan location, five inferred average monthly tandem weights fall outside the confidence area and one failing to identify the existence of damage. This is due to the damage locations being further away from the sensors; thus they have relatively less sensitivity to identify its presence 
Fig. 12 Monthly average tandem weights. a estimated using the inclinometer placed at the left hand support when the damage is at $1 / 4 L$, estimated using the inclinometer placed at the right hand support when the $\mathbf{b}$ damage is at $1 / 2 L$ and $\mathbf{c}$ damage is at $3 / 4 L$. Damage is simulated from July 2012.

to predict the axle weights of a passing vehicle. Once the axle weights of the traffic population are known for some period (e.g., 1 month), generating a plot similar to Fig. 12 does not require any intense data processing effort and could be done using simple software such as Excel, which is widely used among bridge owners/operators. The authors recommend the field validation of the methodology under more realistic conditions (measurement noise, temperature, etc.) in long-term monitoring studies of full-scale bridges as a research area for future investigation. Overall, at this time, the results show that the proposed methodology is a promising tool for the condition assessment of bridges.

\section{Conclusions}

This paper presents a new bridge damage detection concept using information provided by a rotation-based Bridge Weigh-in-Motion system. It is shown that when damage occurs, a rotation based B-WIM system overestimates the weights of a passing vehicle. The inferred tandem weights in 5-axle (Class 9) vehicles are also affected and these errors can be exploited to detect damage. The statistical repeatability of traffic data is investigated using data from a WIM site with data over a 4-year period. It is concluded that:

- Rotation is a parameter that is sensitive to both local and global damage. Hence using a rotation based B-WIM system will give errors in weights which are damage sensitive. If there is a damage in the bridge, the system will generate errors in the weights of passing vehicles which can be used as indicators of damage.

- It is shown in this study that there is statistical repeatability in the tandem weights of Class 9 vehicles which can be used for bridge damage detection.

- The level of sensitivity of rotation to damage is related to the distance of the measurement from the location of damage. The effect of damage is higher for rotation measurements when the damage is closer to the sensor location. This issue is addressed by proposing two inclinometers, one at each end of the bridge.

- The method appears to be insensitive to measurement noise.
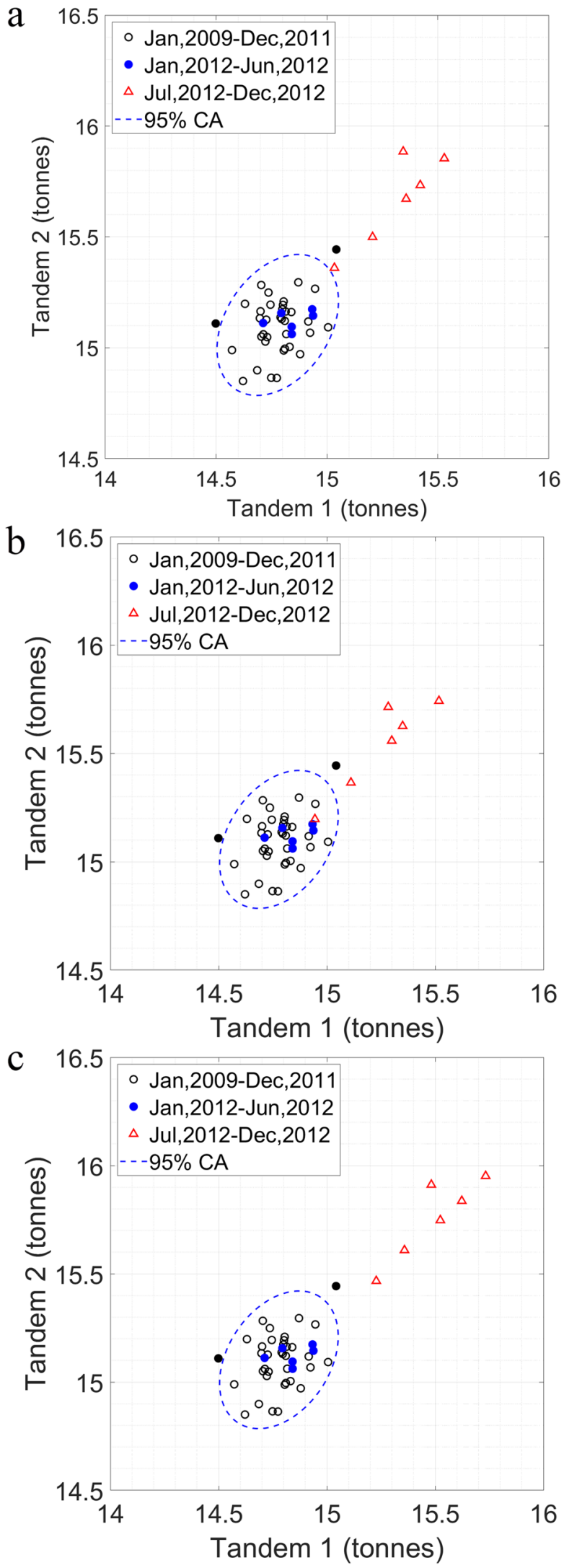
Acknowledgements This research project has received funding from the European Union's Horizon 2020 research and innovation programme under Marie Skłodowska-Curie grant agreement No. 642453.

\section{Compliance with ethical standards}

Conflict of interest The authors declare that they have no conflict of interest.

Open Access This article is licensed under a Creative Commons Attribution 4.0 International License, which permits use, sharing, adaptation, distribution and reproduction in any medium or format, as long as you give appropriate credit to the original author(s) and the source, provide a link to the Creative Commons licence, and indicate if changes were made. The images or other third party material in this article are included in the article's Creative Commons licence, unless indicated otherwise in a credit line to the material. If material is not included in the article's Creative Commons licence and your intended use is not permitted by statutory regulation or exceeds the permitted use, you will need to obtain permission directly from the copyright holder. To view a copy of this licence, visit http://creativecommons.org/licenses/by/4.0/.

\section{References}

1. Žnidarič A, Pakrashi V, O’Brien E, O'Connor A (2011) A review of road structure data in six European countries. Proc Inst Civ Eng Urban Des Plan 164(4):225-232. https://doi.org/10.1680/ udap. 900054

2. Rytter A (1993) Vibration based inspection of civil engineering structures, Department of Building Technology and Structural Engineering, Aalborg University, Denmark

3. Cardini JA, DeWolf JT (2009) Implementation of a long-term bridge weigh-in-motion system for a steel girder bridge in the interstate highway system. J Bridg Eng 14(6):418-423. https:// doi.org/10.1061/(ASCE)1084-0702(2009)14:6(418)

4. O'Brien EJ, Znidaric A, Dempsey AT (1999) Comparison of two independently developed bridge weigh-in-motion systems. Heavy Veh Syst 6(1):147-161. https://doi.org/10.1504/ijhvs.1999.05450 3

5. Ojio T, Carey CH, Obrien EJ, Doherty C, Taylor SE (2016) "Contactless bridge weigh-in-motion. J Bridg Eng 21(7):04016032. https://doi.org/10.1061/(ASCE)BE.1943-5592.0000776

6. Oskoui EA, Taylor T, Ansari F (2020) Method and sensor for monitoring weight of trucks in motion based on bridge girder end rotations. Struct Infrastruct Eng 16(3):481-494. https://doi. org/10.1080/15732479.2019.1668436

7. Moses F (1979) Weigh-in-motion system using instrumented bridges. Transp Eng J ASCE 105(3):233-249

8. Žnidarič A, Kalin J, Kreslin M, Favai P, Kolakowski P (2016) Railway bridge Weigh-in-Motion system. Transp Res Procedia 14(14):4010-4019. https://doi.org/10.1016/j.trpro.2016.05.498

9. Marques F, Moutinho C, Hu W-H, Cunha Á, Caetano E (2016) Weigh-in-motion implementation in an old metallic railway bridge. Eng Struct 123:15-29. https://doi.org/10.1016/j.engst ruct.2016.05.016

10. Liljencrantz A, Karoumi R, Olofsson P (2007) Implementing bridge weigh-in-motion for railway traffic. Comput Struct 85(12):80-88. https://doi.org/10.1016/j.compstruc.2006.08.056

11. O'Connor A, O'Brien EJ (2005) Traffic load modelling and factors influencing the accuracy of predicted extremes. Can J Civ Eng 32(1):270-278. https://doi.org/10.1139/104-092
12. Getachew A, Obrien EJ (2007) Simplified site-specific traffic load models for bridge assessment. Struct Infrastruct Eng 3(4):303311. https://doi.org/10.1080/15732470500424245

13. González A, Rattigan P, Obrien EJ, Caprani C (2008) Determination of bridge lifetime dynamic amplification factor using finite element analysis of critical loading scenarios. Eng Struct 30(9):2330-2337. https://doi.org/10.1016/j.engstruct.2008.01.017

14. Yannis G, Antoniou C (2005) Integration of weigh-in-motion technologies in road infrastructure management. ITE J Institute Transp Eng 75(1):39-43

15. Wang T-L, Liu C, Huang D, Shahawy M (2005) Truck Loading and fatigue damage analysis for girder bridges based on weighin-motion data. J Bridg Eng 10:12-20. https://doi.org/10.1061/ (ASCE)1084-0702(2005)10:1(12)

16. Guo T, Frangopol DM, Chen Y (2012) Fatigue reliability assessment of steel bridge details integrating weigh-in-motion data and probabilistic finite element analysis. Comput Struct 112-113:245257. https://doi.org/10.1016/j.compstruc.2012.09.002

17. Hajializadeh D, Obrien EJ, O'Connor AJ (2017) Virtual structural health monitoring and remaining life prediction of steel bridges. Can J Civ Eng 44(4):264-273. https://doi.org/10.1139/ cjce-2016-0286

18. Cantero D, González A (2014) Bridge . J Bridg Eng 1:1-10. https ://doi.org/10.1061/(ASCE)BE.1943-5592.0000674

19. Cantero D, Karoumi R, González A (2015) The Virtual Axle concept for detection of localised damage using Bridge Weighin-Motion data. Eng Struct 89:26-36. https://doi.org/10.1016/j. engstruct.2015.02.001

20. Gonzalez I, Karoumi R (2015) BWIM aided damage detection in bridges using machine learning. J Civ Struct Heal Monit 5(5):715-725. https://doi.org/10.1007/s13349-015-0137-4

21. Obrien E, Carey C, Keenahan J (2015) Bridge damage detection using ambient traffic and moving force identification. Struct Control Heal Monit 22(12):1396-1407. https://doi.org/10.1002/ stc. 1749

22. Obrien EJ, Quilligan MJ, Karoumi R (2006) Calculating an influence line from direct measurements. Proc Institution of Civil Eng Bridge Eng 159(1):31-34. https://doi.org/10.1680/ bren.2006.159.1.31

23. "Concast Precast Group Concrete Prestressed Girders Technical Guide."

24. Wu C-M, Chuang Y-T (2004) Roll angular displacement measurement system with microradian accuracy. Sensors Actuators A Phys 116(1):145-149. https://doi.org/10.1016/j.sna.2004.04.005

25. Wyler AG (2016) Levelmatic 31 - High precision analog inclination sensor technical specification

26. Bruns DG (2017) An optically referenced inclinometer with submicroradian repeatability. Rev Sci Instrum 88(11):115111. https ://doi.org/10.1063/1.5010202

27. Inaudi D, Glisic B (2002) "Interferometric inclinometer for structural monitoring," in 2002 15th Optical Fiber Sensors Conference Technical Digest. OFS 2002 (Cat. No.02EX533), 1:391-394, https ://doi.org/10.1109/OFS.2002.1000635

28. Hester D, Brownjohn J, Huseynov F, Obrien E, Gonzalez A, Casero M (2020) Identifying damage in a bridge by analysing rotation response to a moving load. Struct Infrastruct Eng 16(7):1050-1065. https://doi.org/10.1080/15732479.2019.16807 10

29. Hester D, Brownjohn JMW, Bocian M, Xu Y (2017) Low cost bridge load test: Calculating bridge displacement from acceleration for load assessment calculations. Eng Struct 143:358-374. https://doi.org/10.1016/j.engstruct.2017.04.021

30. Hester D, Brownjohn J, Bocian M, Xu Y, Quattrone A (2018) Using inertial measurement units originally developed for biomechanics for modal testing of civil engineering structures. Mech 
Syst Signal Process 104:776-798. https://doi.org/10.1016/J. YMSSP.2017.11.035

31. Faulkner K, Huseynov F, Brownjohn J, Xu Y (2018) Deformation monitoring of a simply supported railway bridge under varying dynamic loads

32. Faulkner K, Brownjohn JMW, Wang Y, Huseynov F (2020) Tracking bridge tilt behaviour using sensor fusion techniques. J Civ Struct Heal Monit. https://doi.org/10.1007/s13349-020-00400-9

33. Huseynov F, O'Brien EJ, Brownjohn JMW, Hester D, Chang KC (2020) Bridge damage detection using rotation measurements Experimental validation. Mech Syst Signal Process 135:106380. https://doi.org/10.1016/j.ymssp.2019.106380

34. Helmi K, Taylor T, Zarafshan A, Ansari F (2015) Reference free method for real time monitoring of bridge deflections. Eng Struct 103:116-124. https://doi.org/10.1016/j.engstruct.2015.09.002

35. Walker D, Cebon D (2012) The Metamorphosis of LTPP Traffic Data
36. Leahy C (2013) Using Weigh-in-Motion Data to Predict Extreme Traffic Loading on Bridges. University College Dublin

37. Federal Highway Administration (2016) Traffic Monitoring Guide. 462

38. Zhu XQ, Law SS (2006) Wavelet-based crack identification of bridge beam from operational deflection time history. Int J Solids Struct 43(7-8):2299-2317. https://doi.org/10.1016/j.ijsol str.2005.07.024

Publisher's Note Springer Nature remains neutral with regard to jurisdictional claims in published maps and institutional affiliations. 